\title{
DISTRIBUTION OF KIDNEY BLOOD FLOW: A COMPARISON OF METHOXYFLURANE AND HALOTHANE EFFECTS AS MEASURED BY HEATED THERMOCOUPLE*
}

\section{Kenneth Leighton and Caroline Bruce}

High OUTPUT RENAL FAILURE has been shown to follow the administration of methoxyflurane. ${ }^{1}$ The relationship is apparently dose-dependent. ${ }^{2}$ It would appear that some of the products of metabolism of the drug are responsible for the vasopressin resistant diabetes insipidus that has been well-documented to follow general anaesthesia with this agent. ${ }^{3}$

In particular, the evidence is compelling which links inorganic fluoride, derived from the metabolism of methoxyflurane and the development of renal dysfunction following its administration. ${ }^{3}$

Previous observations have shown that failure of autoregulation of renal blood flow follows the administration of methoxyflurane. ${ }^{4}$ The suggestion was made that such failure may be followed by a change in the intrarenal distribution of blood and that this may influence the handling of the metabolic products of methoxyflurane. This, in turn, might affect the nephrotoxicity of the agent.

Although autoregulation maintains total renal blood flow remarkably constant in the face of alterations in systemic blood pressure, ${ }^{5}$ nevertheless, the distribution of blood is heterogeneous throughout the renal parenchyma. ${ }^{6}$ In ordinary circumstances, the outer cortex receives three-quarters of the total flow of blood to the kidney. The juxtamedullary cortex and the outer medulla receive, in contrast, only about one-fifth of total renal flow. ${ }^{7}$ It is possible for this distribution to alter radically without any marked or even obvious change in total renal blood flow. On the other hand, alterations in distribution may also accompany changes in total flow.

Outer cortical nephrons have shorter tubular systems than those of the deeper and juxtamedullary nephrons. They are relative salt losers when they are compared with deeper nephrons which tend to conserve salt. In addition, outer cortical nephrons have a particularly rich autonomic innervation of the afferent glomerular arterioles and also have considerably larger quantities of renin associated with the juxtaglomular apparatus than is found elsewhere. ${ }^{7}$

The precise functions of these arrangements is open to question, but that they are significant is probably indisputable. Either nervous or hormonal mechanisms (or possibly both) may influence autoregulation of total flow and also the intrarenal distribution of perfusion.

Departments of Anaesthesia and Pharmacology, Faculty of Medicine, The University of British Columbia, Vancouver, Canada. V6T 1W5,

"This work was supported by a grant-in-aid of research awarded by the British Columbia Heart Foundation. 


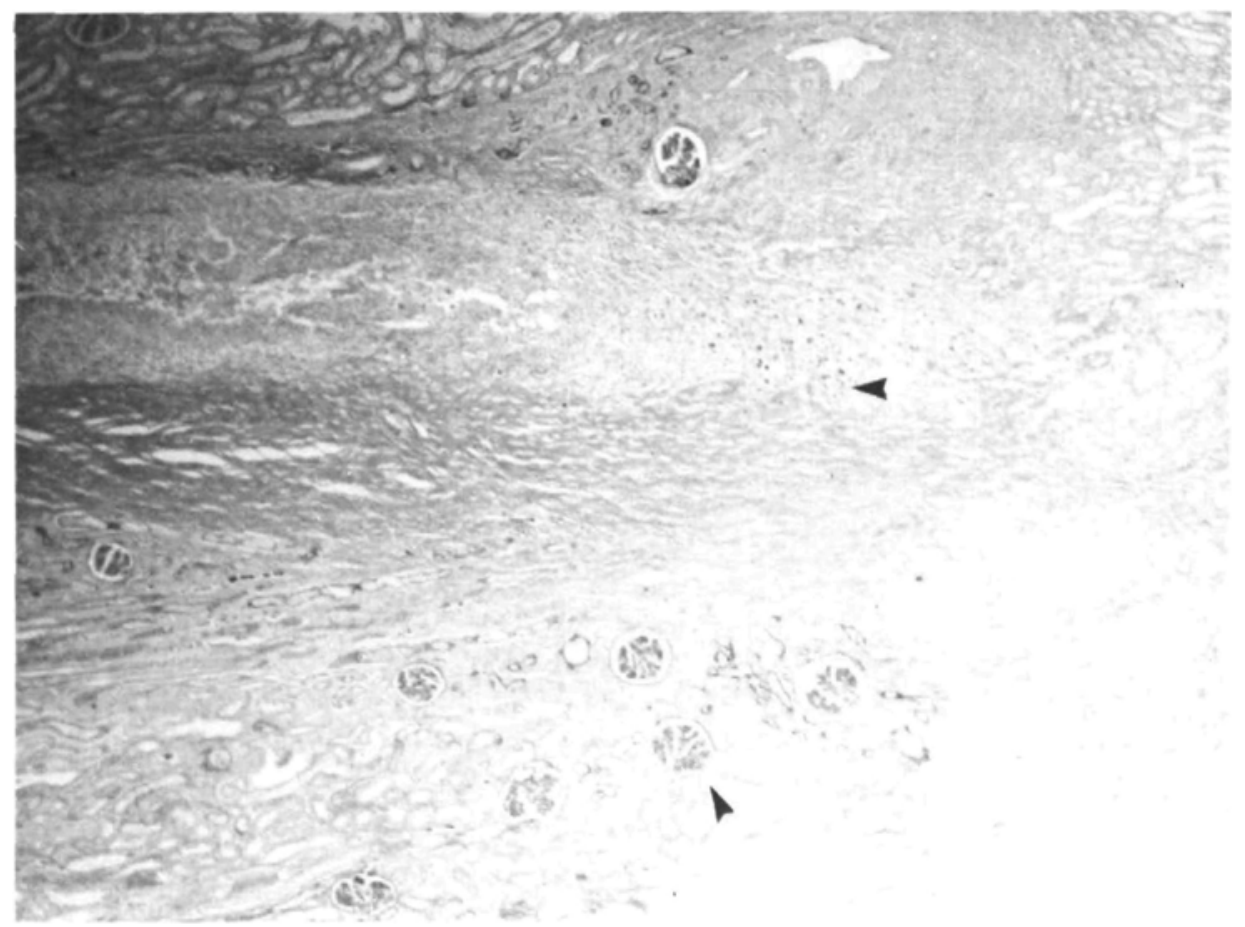

Ficure 1. Low power $\times 50$. Showing thermocouple track (arrow). Diameter $1 \mathrm{~mm}$. Note glomerulus adjacent to track (see Figure 2).

During arterial hypotension, vasoconstriction of the outer cortex can be seen. ${ }^{8}$ The extent of this vasoconstriction is an index of the degree of hypotension. It is probable that this redistribution of blood away from the cortex is the result of nervous (adrenergic) activity, but both locally produced angiotensin and antidiuretic hormone released from the posterior pituitary may play a part in the response. $^{\top}$

'An alteration in the rate of blood flow through the vessels of the juxtamedullary nephrons will alter flow rates through the vasa recta which take origin from the glomerular efferents of these nephrons. This alteration in vasa recta flow may affect the osmolarity of the medullary interstitium. Increased flow through the vasa recta reduces interstitial osmolarity. This, in turn, will influence the concentration of urine as it is presented to the distal tubular system. A raised concentration of potentially toxic ions may be delivered and this may be followed by an enhanced effect upon susceptible tissues.

It appears to be obvious, therefore, that not only is total renal blood flow of significance, but the distribution of blood within the kidney has an important bearing upon the function of the organ.

Total renal blood flow is subject to autoregulation. If autoregulation be affected and perhaps abolished by an agent such as methoxyflurane, then it is possible that this anaesthetic may also affect the intrarenal distribution of blood.

Several methods have been employed to observe the distribution of renal blood 


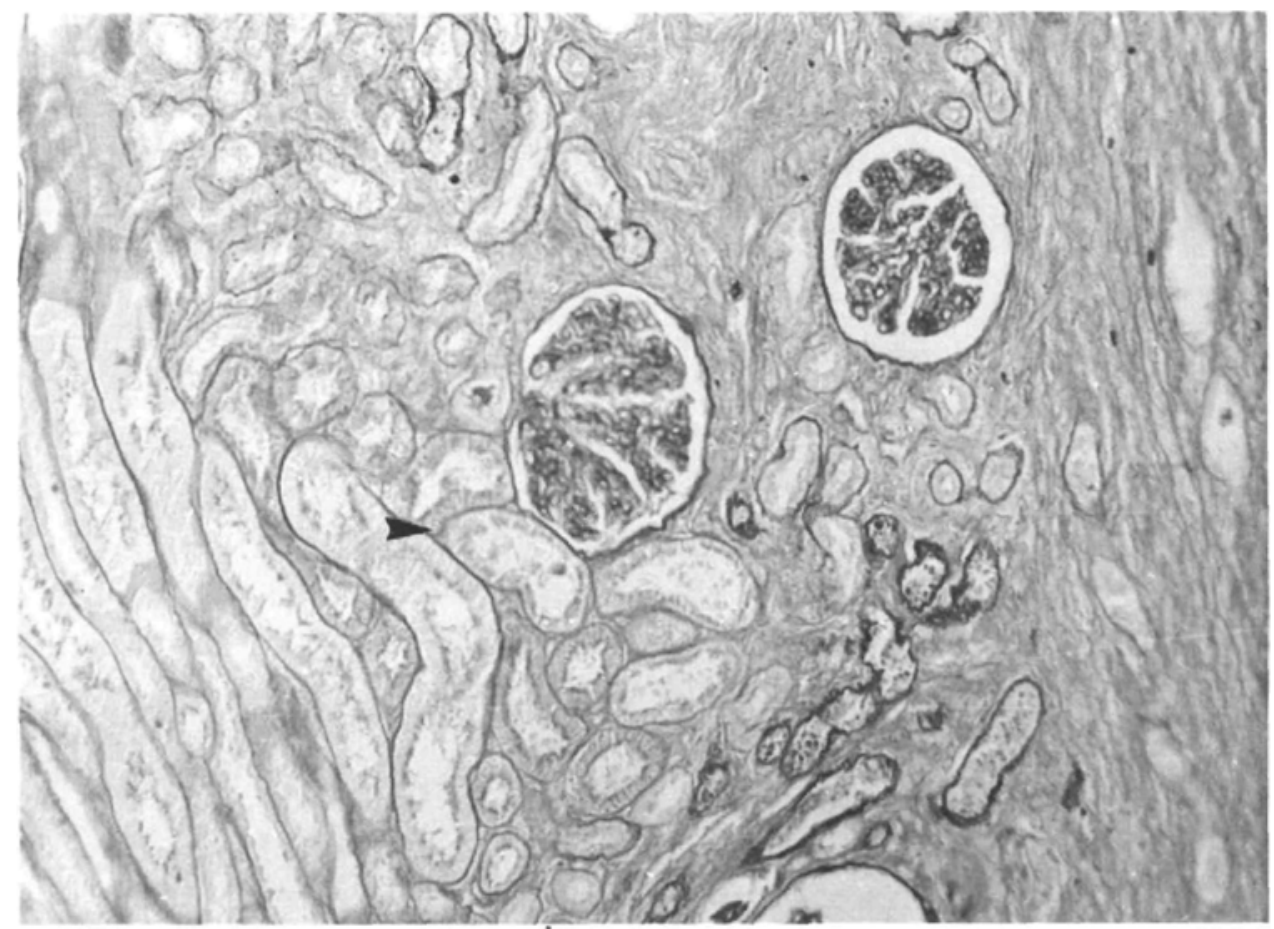

FIcUne 2. Medium power $\times 300$. Showing thermocouple track and glomeruli immediately adjacent to it. Note absence of histological evidence of damage to glomeruli or tubules.

flow. In one popular method, ${ }^{86} \mathrm{Kr}$ is injected into a renal artery and its rate of disappearance is followed. Three or four components of the decay curve can be plotted. ${ }^{\theta}$ By autoradiography these components can be shown to reflect the perfusion of various areas of the kidney, from outer cortex to perirenal fat. This method of studying renal perfusion presents problems when repeated observations are made in chronic animal preparations. These problems are not insurmountable, but remain considerable. ${ }^{10}$

Another method of observing perfusion in a variety of tissues, but which is particularly applicable to such organs as the heart, liver and kidney, is to employ the heated thermocouple technique. First described by Gibbs, ${ }^{11}$ as a modification of the thermostromuhr of Rein, ${ }^{12}$ and subsequently considerably modified and extensively investigated by Grayson, ${ }^{13,14}$ the heated thermocouple has proved itself a useful tool and one which can satisfactorily be employed in chronic preparations. Repeated observations can be made since only a small quantity of heat is applied to the thermocouple. This is rapidly dissipated. The heat acts as a tracer and appears to produce no local alterations in function and only slight structural damage. This is illustrated in figures 1,2 and 3 which show a renal cortex where a heated thermocouple has been chronically implanted. As can be seen, the tissue damage due to the thermocouple is strictly localised and functioning glomeruli and tubules are in close proximity to the thermocouple track.

In Grayson's technique, heat is applied in cyclical fashion to a thermocouple. 


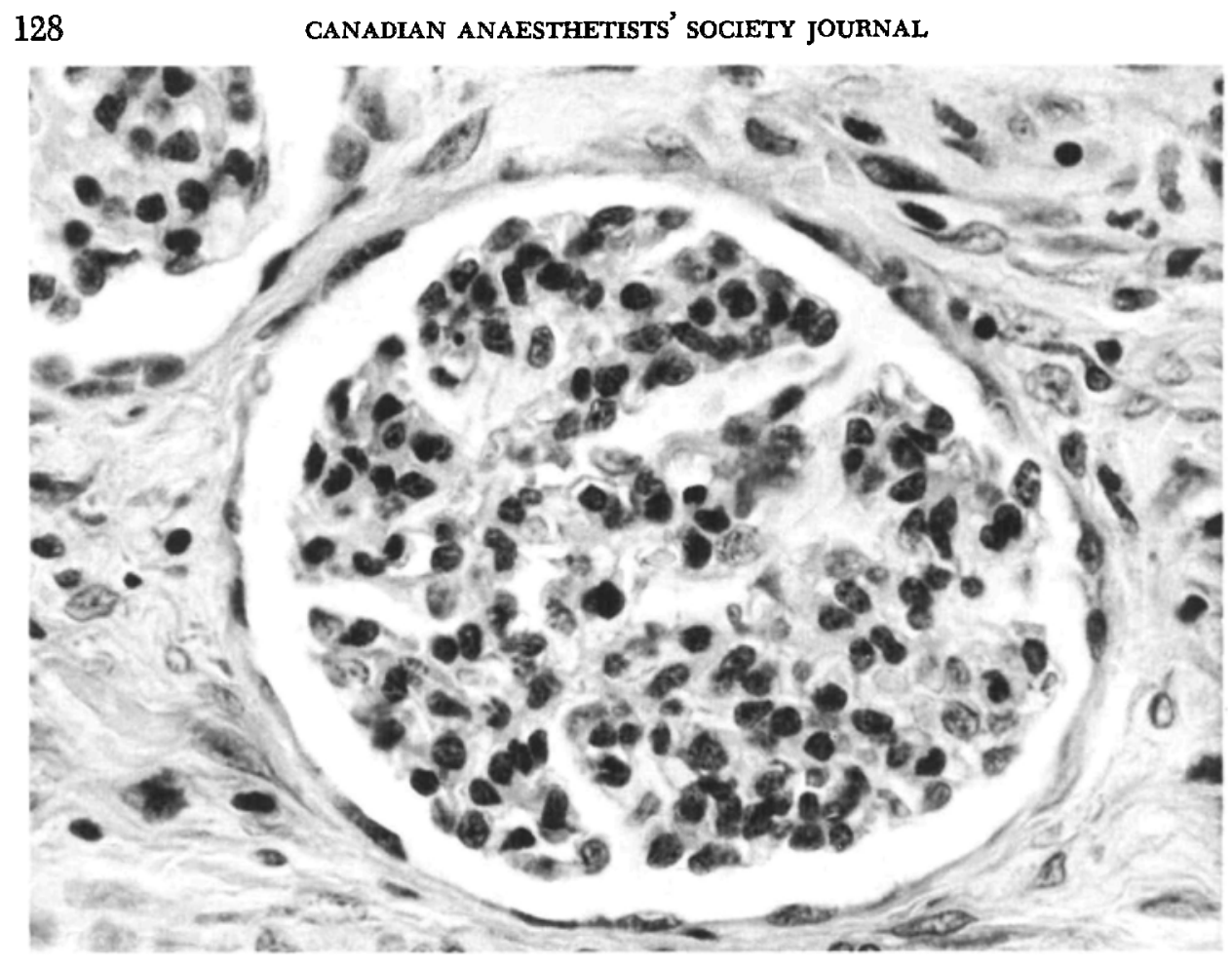

FIcure 3. High power $\times 800$. Showing glomerulus within $100 \mu$ of thermocouple track, No evidence of damage.

Alterations in the temperature difference between "hot" and "cold" (or reference) junctions are thus a measure of the heat supplied to the hot junction and its rate of dissipation. Repeated cycles of current are applied to a heating coil. This coil is placed close to a copper-constantan thermocouple ("hot" junction). The whole is embedded in an organ or tissue mass. The reference thermocouple ("cold" junction) is maintained at a constant temperature. Alterations in the output from the thermocouple system are therefore a function of changes in the heat clearance (or thermal conductivity) of the organ or tissue.

When tissue temperatures are constant, apparent alterations in thermal conductivity are directly related to changes in tissue perfusion.

In the apparatus described by Grayson, the output from the thermocouple shows a period of zero voltage which is followed by a plateau of raised voltage (when current is first supplied to the heater coil). This plateau is referred to as the "lower equilibrium". This is followed by a brief voltage spike (which follows the application of a "booster" current to the coil). A second plateau then follows ("upper equilibrium") and, once again, zero voltage (Figure 4). The period of time from cycle to cycle is 80 seconds. Changes in apparent thermal conductivity of the tissue in which the thermocouple is placed are shown by alterations in the distance between the two periods of equilibrium displayed on the record. This distance is referred to as $\theta$ and it is, in fact, the temperature increment observed in response to heating the thermocouple. 


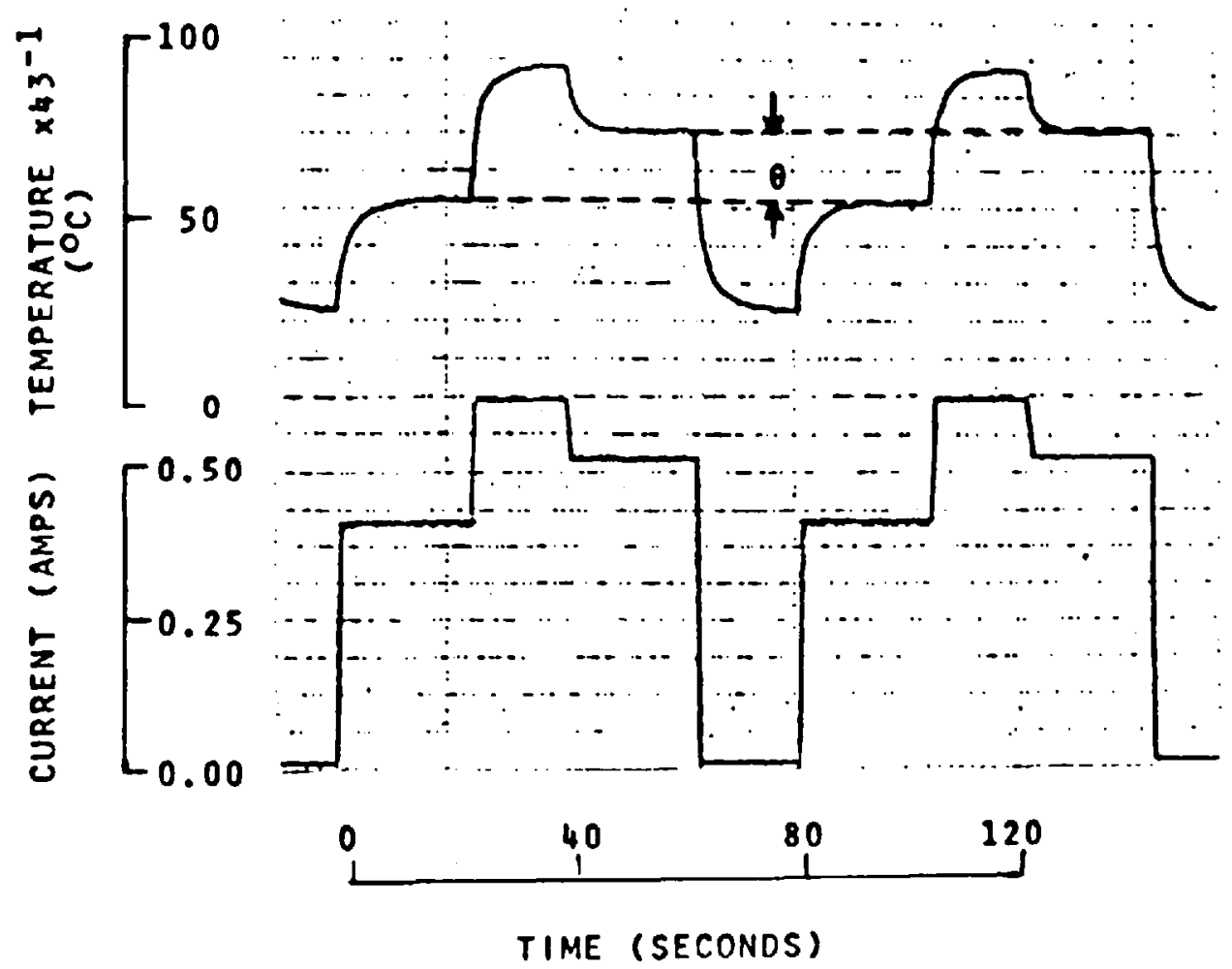

FIGURE 4. Heated thermocouple record. Upper trace: temperature record; lower trace: current cycle. Note: the dotted lines joining the lines of equilibrium for descriptive purposes. $\theta$ (temperature increment) is the measured distance between upper and lower equilibria. As perfusion decreases and heat clearance diminishes, so local temperature rises in response to heating and this is reflected by an increase in the value of $\theta$ (from Grayson et al. J. Appl. Physiol. 30: 251, 1971 (with permission).

Grayson has shown ${ }^{13}$ that Carslaw's equation for the heating of a sphere in an infinite mass applies in the circumstances of the heated thermocouple,

$$
\text { thus: } I^{2} \mathrm{R}=4 \pi \mathrm{r} \theta \mathrm{K} \text { (Carslaw's equation) }
$$

where $I$ is heating current, $R$ heater resistance, $r$ the radius of the sphere, $\theta$ the temperature increment produced and $\mathrm{K}$ the thermal conductivity of the substance (or tissue) under observation.

When $I$ is constant, then $\theta$ and $\mathrm{K}$ are related in a linear fashion. ${ }^{13}$

Tissue perfusion can be assessed by means of heated thermocouples. $\theta$ readings are obtained from the output of the instrument. $\theta$ values will change with heat clearance and this, in turn, is an index of local tissue thermal conductivity.

As heat clearance decreases, $\theta$ will increase in magnitude.

Thus, in general terms, as local perfusion increases, $\theta$ values will decline.

Grayson has shown that the heated thermocouple "observes" a sphere of tissue some $5 \mathrm{~mm}$ by $3 \mathrm{~mm}$.

If the administration of methoxyflurane leads to an alteration in the distribution 
of renal perfusion, it follows that there will be a concomitant change in heat clearance. This can be detected by the heated thermocouple technique.

Therefore, by implanting heated thermocouples in the kidney and observing heat clearance following alterations in the inspired concentrations of methoxyflurane, it should be possible to detect any changes in the distribution of blood flow which occur. Observations of such alterations in the distribution of perfusion can be made in whatever portion of the renal parenchyma the thermocouples are placed.

Any such redistribution of intrarenal blood flow may be of significance in the production of renal damage and in the development of disturbances in function.

In the present experiments, simultaneous estimations of total flow and regional perfusion were made in the kidney of the dog. Doppler flow probes and heated thermocouples were employed to study these two parameters. The effects of methoxyflurane and halothane upon these estimations were then assessed.

\section{Method}

Chronic preparations of mongrel dogs were employed. Preparation involved implanting heated thermocouples in the outer and inner cortices of the left kidney through an extraperitoneal approach by way of a flank incision.

One thermocouple was implanted in the superficial cortex (at least $3 \mathrm{~mm}$ below the capsule) and a second thermocouple was placed deeper in the cortex and as close as possible to the juxtamedullary region without actually penetrating the medulla. The depth required for these implants was determined over a number of experiments by trial and error. The satisfactory placement of the thermocouples was confirmed in all cases by post mortem dissection. Reference junctions were placed in the perinephric fat.

Leads from the thermocouples were brought subcutaneously to the back of the animal's neck and there exteriorized.

A Doppler ultrasonic flow probe (Park's Electronics, Beaverton, Oregon) was placed around the renal artery of the same kidney and the leads were similarly exteriorized.

Experiments were performed following induction of anaesthesia with thiopentone $(20 \mathrm{mg} \mathrm{Kg}$ ). The trachea was intubated. The animals were ventilated (by means of a Harvard Pump) with either oxygen and methoxyflurane or oxygen and halothane. Methoxyflurane was supplied by a Pentec (Mark 2). vaporiser ${ }^{*}$ and halothane by a Drager vaporiser. $\dagger$

The femoral artery was cannulated and by this means arterial blood gases were sampled and blood pressure recorded. Blood gases were estimated by means of a Radiometer $\mathrm{O}_{2}$ and $\mathrm{CO}_{2}$ electrode system and blood pressure was recorded through a Statham transducer (P23) and a Grass recorder (Model 7).

The output from the thermocouples was displayed on a Rikadenki recorder (B-104) and on a Beckman Recorder (\#1005).

${ }^{\circ}$ Courtesy Abbott Laboratories.

tCourtesy Hoechst Pharmaceuticals. 
The temperature of the animals was maintained at $38^{\circ} \mathrm{C}$ by means of a water blanket.

Blood gas indices were maintained at $\mathrm{Po}_{2}$ greater than $100 \mathrm{~mm} \mathrm{Hg} . \mathrm{Pco}_{2}$ between $30-40 \mathrm{~mm} \mathrm{Hg}$ and $\mathrm{pH}$ between 7.35 and 7.44.

$5 \%$ dextrose and water was administered intravenously throughout the experiments at the rate of $50-60 \mathrm{mls}$ per hour.

In all experiments a stable blood pressure reading of $100 \mathrm{~mm} \mathrm{Hg}$ was obtained. Anaesthesia was then deepened by increasing the inspired concentration of either methoxyflurane or halothane until the mean arterial blood pressure was reduced to a stable level of $70 \mathrm{~mm} \mathrm{Hg}$. Observations were again made of total flow and regional perfusion and anaesthesia was once again deepened until a stable mean arterial pressure of $45 \mathrm{~mm} \mathrm{Hg}$ was reached. Flow and perfusion readings were taken once more and then the pressure was allowed to rise again to $70 \mathrm{~mm} \mathrm{Hg}$ (by lowering the inspired anaesthetic concentration). Readings were once again taken at this restored blood pressure.

\section{RESULTS}

Eight dogs were employed in 20 experiments. Nine experiments were made during methoxyflurane administration and 11 during halothane administration.

In each experiment only one anaesthetic (halothane or methoxyflurane) was administered. Experiments were in some cases performed (see Table I) on animals which had already been subjected to anaesthesia. An interval of at least four days separated such repeat observations.

Figure 5 illustrates typical (time condensed) observations made during one experiment on a dog anaesthetised with halothane. It should be observed that, as mean arterial pressure falls below $70 \mathrm{~mm} \mathrm{Hg}$, total renal blood flow also falls and flow becomes completely pressure-dependent. (This phenomenon is wellknown. $)^{4,6}$

The mean percentage difference in $\theta$ readings at $70 \mathrm{~mm} \mathrm{Hg}, 45 \mathrm{~mm} \mathrm{Hg}$ and $70 \mathrm{~mm} \mathrm{Hg}$ (mean arterial blood pressure) compared with that at $100 \mathrm{~mm} \mathrm{Hg}$ was determined and expressed graphically with standard errors as shown in Figures 6 and 7 . Table $I$ lists the percentage alterations in $\theta$ values.

The percentage change of outer and inner cortical $\theta$ readings were then compared and subjected to statistical analysis (Mann-Whitney U Test). In the case of methoxyflurane, outer cortical flow clearly differed from deep cortical flow $(\mathrm{P}=<0.05$ at $70 \mathrm{~mm} \mathrm{Hg} ; \mathrm{P}=<0.01$ at $45 \mathrm{~mm} \mathrm{Hg}$ and $\mathrm{P}=<0.01$ at $70 \mathrm{~mm} \mathrm{Hg}$ ).

In the case of halothane, $\theta$ values in the outer and inner cortices did not differ significantly.

The directional changes and the difference between the two agents are clearly illustrated in Figures 6 and 7.

\section{Discussion}

From these experiments it appears that methoxyflurane and halothane have different effects upon the intrarenal distribution of blood flow. If a steady state is 
$\boldsymbol{\theta}_{\mathrm{s}}$
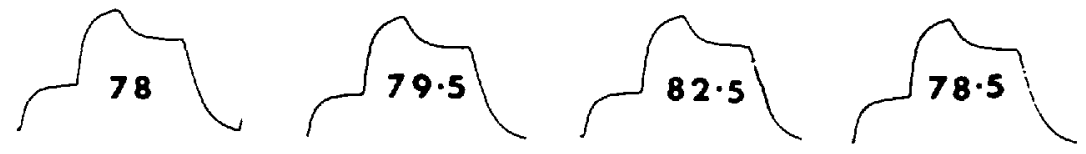

$\boldsymbol{\theta}_{\mathrm{d}}$
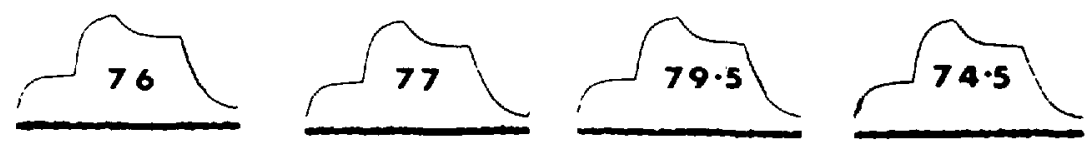

RBF
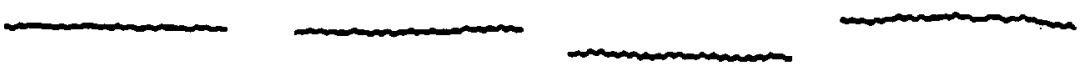

MAP

$100 \mathrm{~mm} \mathrm{Hg}$

$70 \mathrm{~m} \mathrm{~m} \mathrm{H}_{\mathrm{g}}$

$45 \mathrm{~m} \mathrm{~m} \mathrm{He}$

$70 \mathrm{~m} \mathrm{mg}$

Figure 5. A typical (time condensed) series of observations. $\theta_{\theta}, \theta_{d}$ are heated thermocouple outputs from superficial and deep renal cortices respectively. $\theta$ is measured in microvolts. RBF represents renal blood flow (showing directional change only). MAP $=$ mean arterial blood pressure. (Time elapsed: $100-70 \mathrm{~mm} \mathrm{Hg} 16 \mathrm{~min} ; 70-45 \mathrm{~mm} \mathrm{Hg} 6.6 \mathrm{~min}$; $45-70 \mathrm{~mm} \mathrm{Hg} 9.3 \mathrm{~min}$.)

produced during a methoxyflurane anaesthetic and anaesthesia is then deepened by increasing the inspired concentration of this agent, there is a significant alteration in the relationship between the perfusion of outer and inner renal cortex. This is not the case with halothane.

The redistribution of intrarenal blood flow such that there is a relative increase in juxtamedullary flow at the expense of outer cortical perfusion might have important consequences for renal function. Our observations indicate that this redistribution accompanies the administration of methoxyflurane and that the redistribution is apparent both before and after the failure of autoregulation of total renal blood flow consequent upon a fall in mean arterial pressure below $70 \mathrm{~mm} \mathrm{Hg}$.

Since perfusion and glomerular filtration may be intimately related, a relatively greater diminution in outer cortical perfusion at least suggests the possibility of a greater diminution in filtration in this area of the cortex than in the inner and juxtamedullary cortex. In other words, a relative diversion of perfusion from outer to inner cortex is likely to be accompanied by a relative diminution in outer cortical filtration. 


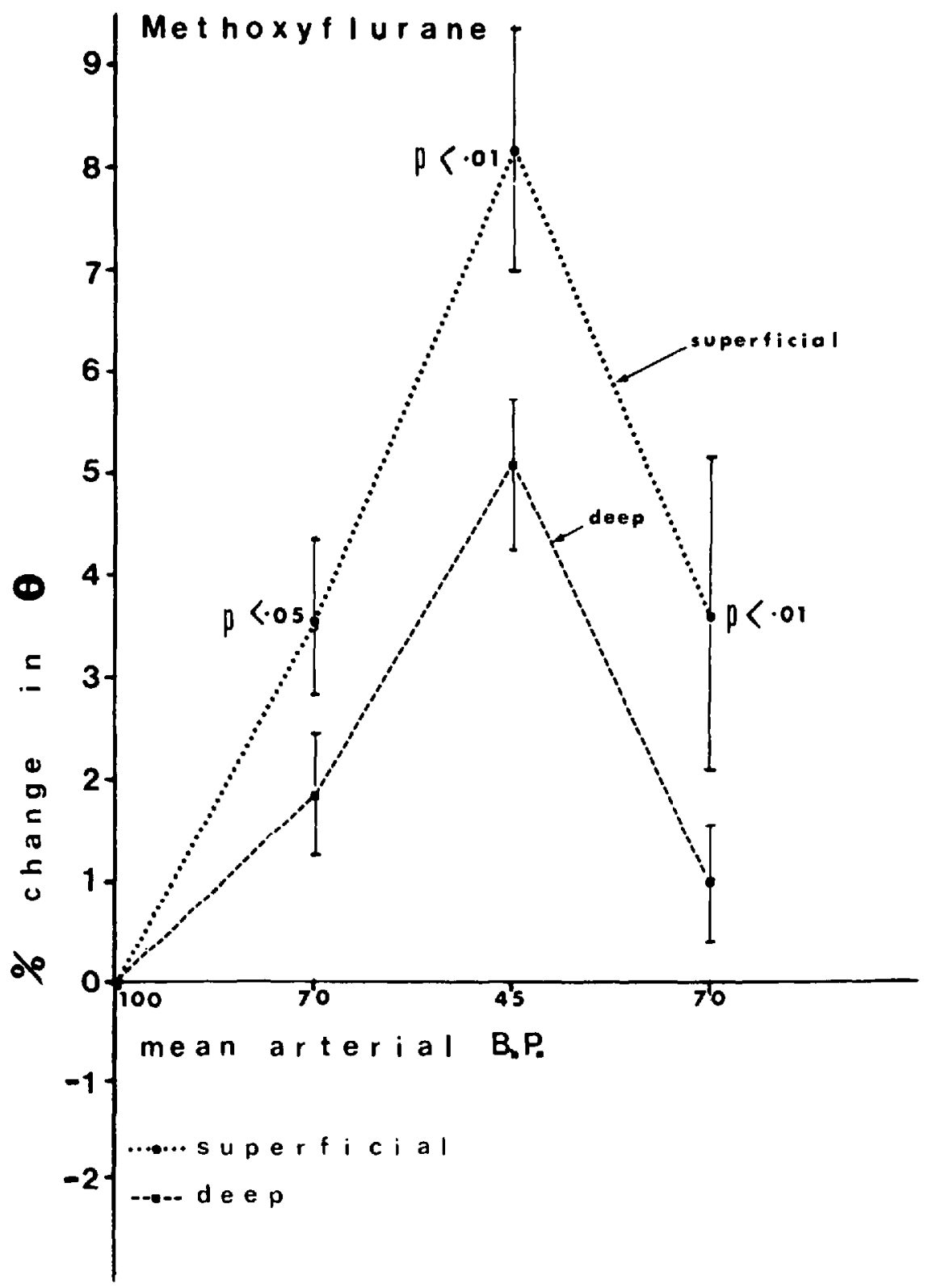

Figure 6. Illustrating percentage alteration in $\theta$ readings in both superficial and deep cortical thenmocouples in response to altering methoxyflurane concentrations (as evidenced by varying arterial pressures). Heat clearance and therefore tissue perfusion bear an inverse relationship to $\theta$ changes. Number of experiments $(n)=9$.

If $\mathrm{F}^{+}$damage to tubular epithelium is related to the time which this ion is in contact with the epithelium, then prolongation of such contact as may occur when more of the $\mathrm{F}^{+}$is excreted via the slower flowing nephrons is likely to increase tubular damage.

When the known association between the administration of methoxyflurane and 


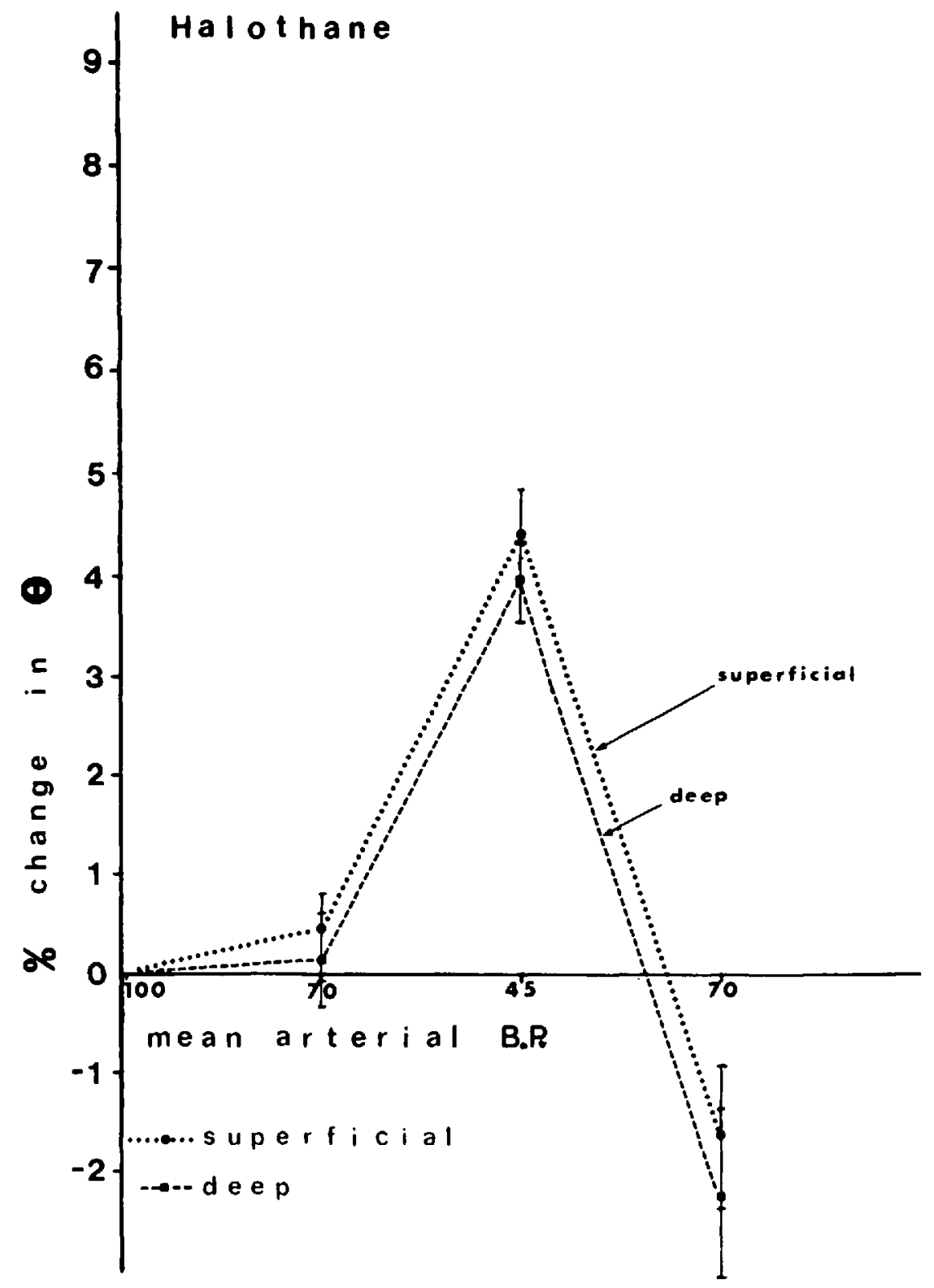

Ficure 7. As for Figure 6 with halothane substituted for methoxyflurane (see text). $n=11$.

the development of high output renal failure is considered, the ability of this agent to alter renal perfusion may be of some importance in influencing the severity, if not the development, of the dysfunction.

That $\mathrm{F}^{+}$in the free ionic form is intimately associated with the renal toxicity of methoxyflurane is not in dispute. The suggestion is made here that blood flow alterations which this agent produces may contribute to the development and the severity of the toxicity. The importance of this contribution is, of course, unknown. 
However, the development of nephrotoxicity appears to be the major contraindication to the employment of methoxyflurane in clinical practice. In other respects, the agent is a satisfactory anaesthetic.

As far as the effects of methoxyflurane on intrarenal blood flow are concerned, it is possible to envisage a pharmacological agent which might mitigate or reverse these effects and lead to the restoration of the normal balance of perfusion in the outer and inner renal cortex. This restoration might permit a more rapid excretion of $\mathrm{F}^{+}$with a diminution of tubular transit time and, thus, a reduction in tubular damage.

\section{ACKNOWLEDGMENTS}

The authors wish to acknowledge with gratitude the help of the following: Dr. M.C. Sutter, Professor and Head, Department of Pharmacology, U.B.C., who kindly offered criticism and advice; Mr. Charles Culling, F.I.M.L.T., F.R.M.S., Associate Professor, Department of Pathology, U.B.C., who prepared and photographed the histological sections; Mr. T. Richardson, B.Sc., who carried out the statistical analyses; Mr. Richard Machin, Summer Student from the Faculty of Dentistry, U.B.C., and Mr. Glenn Collins (Illustrations).

\section{SUMMARY}

Heated thermocouples have already proved their worth in assessing tissue perfusion. The principle involved is that of heat clearance. This technique has been employed to investigate the distribution of renal blood flow with particular reference to outer and inner cortical perfusion. The effect of varying the depth of anaesthesia with methoxyflurane and halothane upon the intrarenal distribution of blood flow has been studied. Methoxyflurane (but not halothane) appears to promote a reduction in outer cortical perfusion and a relative increase in inner cortical perfusion. This may be significant in the production of nephrotoxicity by methoxyflurane, since it may lead to a more prolonged tubular contact with the toxic products of methoxyflurane metabolism.

\section{RÉSUMÉ}

Les thermocouples chauffés ont fait leur preuve pour mesurer la perfusion tissulaire. Le principe évoqué est celui de la "perte de chaleur". Cette technique a été utilisée pour évaluer la distribution du débit sanguin rénal, avec attention particulière à la perfusion corticale superficielle et corticale profonde. Nous avons étudié l'effet de la variation de la profondeur de l'anesthésie avec l'halothane et le méthoxyflurane sur la distribution du débit sanguin intra-rénal. Le méthoxyflurane (mais pas l'halothane) donne une diminution de la perfusion corticale superficielle + une augmentation relative de la perfusion corticale profonde. Ceci peut être significatif dans la production de la néphrotoxicité au méthoxyflurane. Car cette augmentation de la perfusion corticale profonde prolongerait le contact des métabolites du méthoxyflurane avec les tubules rénaux. 


\section{REFERENCES}

1. Crandell, W.B., Pappas, S.G., \& MacDonald, A. Nephrotoxicity associated with methoxyflurane anresthesia. Anesthesiology 27:591 (1966).

2. Mazze, R.I., Shue, G.L., \& Jackson, S.H. Renal dysfunction associated with methoxyflurane anesthesia: a randomized prospective clinical evaluation. J.A.M.A. 216: 278 (1971).

3. Mazze, R.I., Thudell, J.R., \& Cousins, M.J. Methoxyflurane metabolism and renal dysfunction: clinical correlation in man. Anesthesiology 35: 247 (1971).

4. Leichton, K.M., Koth, B., \& Wenkstenn, D. Autoregulation of renal blood flow: alteration by methoxyflurane. Canad. Anaesth. Soc. J. 20: 173 (1973).

5. Thurau, K. Renal hemodynamics. Am. J. Med. 36: 698 (1964).

6. Bargen, A.C. \& Herd, J.A. The renal circulation. New Eng. J. Med. 284: 482 (1971).

7. Folkow, BJoRn, \& NeIL, E. Circulation. Oxford University Press, London and Toronto (1971).

8. Hollenberg, N.K., Epstein, M., \& Rosen, S.M. Acute oliguric renal failure in man evidence for preferential renal cortical ischemia. Medicine (Balt.) 47: 455 (1968).

9. Thonbunn, G.D., Kopald, H.H., Herd, J.A., Hollenberg, M., O’Morchoe, C.C.C., \& BARGER, A.C. Intrarenal distribution of nutrient blood flow determined with $\mathrm{Kr}^{85}$ in the unanesthetised dog. Circ. Res. 13: 290 (1963).

10. Rosen, S.M. Intrarenal distribution of blood flow in the transplanted kidney: effect of denervation and rejection. J. Clin. Invest. 46: 1239 (1967).

11. Gibus, F.A. A thermoelectric blood flow recorder in the form of a needle. Proc. Soc. Exptl. Biol, Med. 31: 141 (1933).

12. Rein, H. Die Thermo-Stromuhr Ein Verfalsen Zur Fortlangenden Messung Der Mittferen Aboluten Durch Flussmenger in Mideroffutten Geffassen in situ. Z. Biol. 87: (1927-28).

13. Grayson, J. Internal calorimetry in the determination of thermal conductivity and blood flow. J. Physiol. (London) 118: 54 (1952).

14. Grayson, J., Coulson, R.L., \& Winchester, B. Internal calorimetry-assessment of myocardial blood flow and heat production. J. Appl. Physiol. 30: 251 (1971). 